\title{
Virtual ignition of a methane leak by electric spark
}

\author{
Nicolae-Ioan Vlasin ${ }^{1,}$, Emilian Ghicioi ${ }^{1}$, Vlad Mihai Păsculescu ${ }^{1}$, Marius Simion Morar ${ }^{1}$, \\ and Laurențiu Munteanu ${ }^{1}$ \\ ${ }^{1}$ National Institute for Research and Development in Mine Safety and Protection to Explosion, \\ Petrosani City, G-ral. Vasile Milea Street 32-34, Hunedoara county, 332047, Romania
}

\begin{abstract}
In the virtual environment, respectively in a rectangular tube with a hole at one end, a computational simulation was performed comprising two stages: the first stage aims at simulating a methane gas leak through a hole in the floor of the tube and its diffusion in the air of which the inner volume of the virtual environment is constituted. At the full end of the tube is arranged an electric ignition source that activates in parallel with the gas source, being observed the formation of the explosive mixture in the proximity of the ignition source and the moment of initiation of the explosive atmosphere. The second stage of the simulation is marked by a higher level of velocities characteristic of the explosive process of the airmethane mixture, which involves the use of different settings. The host of the computer simulation is the Fluent application of the ANSYS platform. Post-processing is performed both on the ANSYS platform, through the Fluent and Results applications and through the facilities offered by the Tecplot 360 application.
\end{abstract}

\section{Introduction}

Most of the times, in the expertise of a gas explosion event, the concentration of the entire volume in which it occurred is taken into account [1]. Relative to the volume of the analysed domain, the volume of combustible gas calculated to form an explosive atmosphere [2] will be different from the real one. Two cases can be encountered:

- the ratio between the volume of combustible gas and the entire volume of the affected space is higher than the real one. In this case, the distance between the gas source and the initiation source is relatively large, the local value of the gas concentration in the proximity of its source reaching the explosive range much earlier than at the location of the ignition source;

- the ratio between the volume of combustible gas and the total volume of the affected space is lower than the real one. In this case, the distance between the gas source and the initiation source is relatively small, the local value of the gas concentration in the vicinity of the ignition source reaching the explosive range earlier than the concentration value [3] on the entire analysed volume.

\footnotetext{
${ }^{*}$ Corresponding author: nicolae.vlasin@insemex.ro
} 
The case of perfect homogeneity is unlikely to exist in reality [4] and has therefore not been considered.

Even when it comes to smaller volumes, the distance between the source of combustible gas and the source of initiation makes an essential contribution to the formation of the explosive mixture [5]. At the same time, an important contribution is made by air currents due to cold walls, heating sources or those formed between two open surfaces, etc.

In order to observe the phenomenon of ignition [6] of an explosive atmosphere near a source of combustible gas, in the virtual domain a rectangular tube was built in which a methane gas leak was simulated. An ignition source was positioned at one end of the tube and an explosion pressure release hole was configured at the opposite end of the tube. The methane gas leak was simulated through an irregular surface on the floor of the tube.

The computational simulation was performed through the ANSYS platform, for gas leakage and methane ignition being used the Fluent application. The simulation results were highlighted both in Fluent and using another application dedicated to the study of CFD (Computational Fluid Dynamics) - Tecplot - application usually used by our researchers to interpret the results given by PIV (Particle Image Velocimetry) systems [7].

\section{Geometry and mesh setups}

As previously mentioned, the geometry consisted of a rectangular tube (Figure 1) with a length of $1000 \mathrm{~mm}$ and a section of $100 \times 100 \mathrm{~mm}$. For convenience, the coordinate system was positioned on the longitudinal axis of the tube, $5 \mathrm{~mm}$ from the closed end, following that in the origin of this coordinate system to be positioned the ignition source.

In order to release the explosion pressure, at the opposite end of the tube was cut a square hole with a side of $30 \mathrm{~mm}$ and with the centre on the longitudinal axis of the tube.

Considering the simulation of the methane gas leak, on the floor of the rectangular tube, at $55 \mathrm{~mm}$ from its full end, an irregular surface with an area of $66,817 \mathrm{~mm}^{2}$ was created.

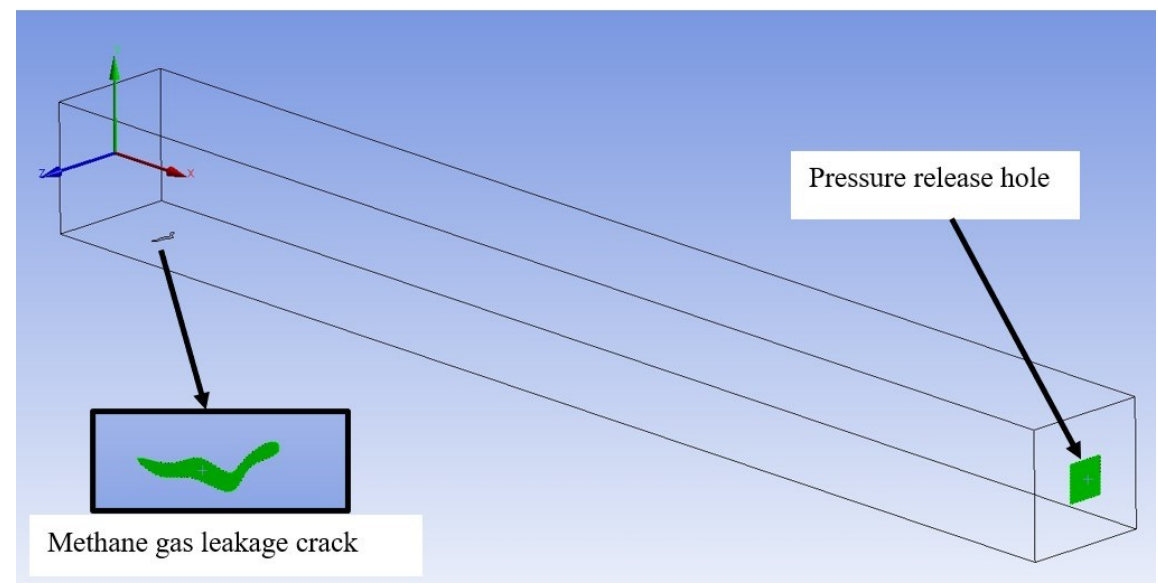

Fig. 1. The geometry of the rectangular tube and the arrangement of the holes

The internal volume of the tube was intentionally left empty (without solid obstacles) to facilitate the unobstructed dispersion of methane. The arrangement of some objects inside this volume would have led to a different pattern of dispersion that is not the purpose of this work.

In the process of discretization of the geometry, the sensitive area of the simulation was taken into account, respectively the location of the gas leak and that of the source of initiation 
of the explosive mixture. Thus, a much finer discretization network was set for this area than in the rest of the tube. Figure 2 represents a longitudinal section of the discretized tube, in the area of the refined mesh being found both the location of the ignition source (origin of the coordinate system) and the source of combustible gas (crack in the floor of the tube).

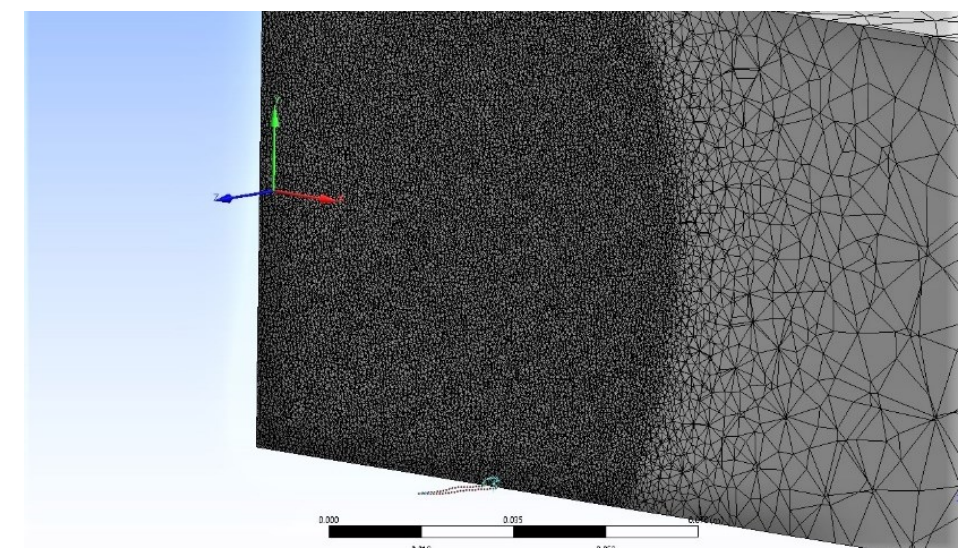

Fig. 2. Longitudinal section of the discretized tube in finite volumes

\section{Computational simulation}

Because the processes of methane diffusion and that of initiation of the explosive atmosphere differ greatly in terms of velocity regime, the computer simulation was divided into two stages, each with its own settings. Both stages were set and run in the ANSYS Fluent application.

\subsection{Stage 1. Formation of the explosive atmosphere}

The explosive atmosphere inside the rectangular tube was virtually created by setting the crack in the floor of the tube as a methane gas inlet (see Figure 1). The explosion pressure release hole was configured as the free surface (outlet), with an initial pressure of $101325 \mathrm{~Pa}$, pressure also imposed on the air inside the rectangular tube.

Due to the reduced distance between the gas source and the initiation location, for the introduction of the combustible gas in the analysed domain, a 45 degrees angle was chosen, oriented towards the free exit of the tube. The gas inlet pressure was set to $101825 \mathrm{~Pa}$ and a temperature value of $283 \mathrm{~K}$.

The other elements of the analysed domain had initial temperature values of $283 \mathrm{~K}$ for outlet, $288 \mathrm{~K}$ for walls and $291 \mathrm{~K}$ for the inside of the rectangular tube.

Figure 3 shows, on a longitudinal section of the tube, the colour contours (on a scale from 0 to 1 ) of the $\mathrm{CH}_{4}$ mol fraction derived from the gas leakage and the location of the ignition source. The image was obtained in the Tecplot application.

Using a 3D representation of the tube and its longitudinal section on the vertical axis of symmetry, by highlighting the current lines formed by the gas leak, we can see the asymmetric arrangement of the fluid flow, with an uneven distribution of methane concentrations relative to the vertical plane of symmetry (Figure 4). 


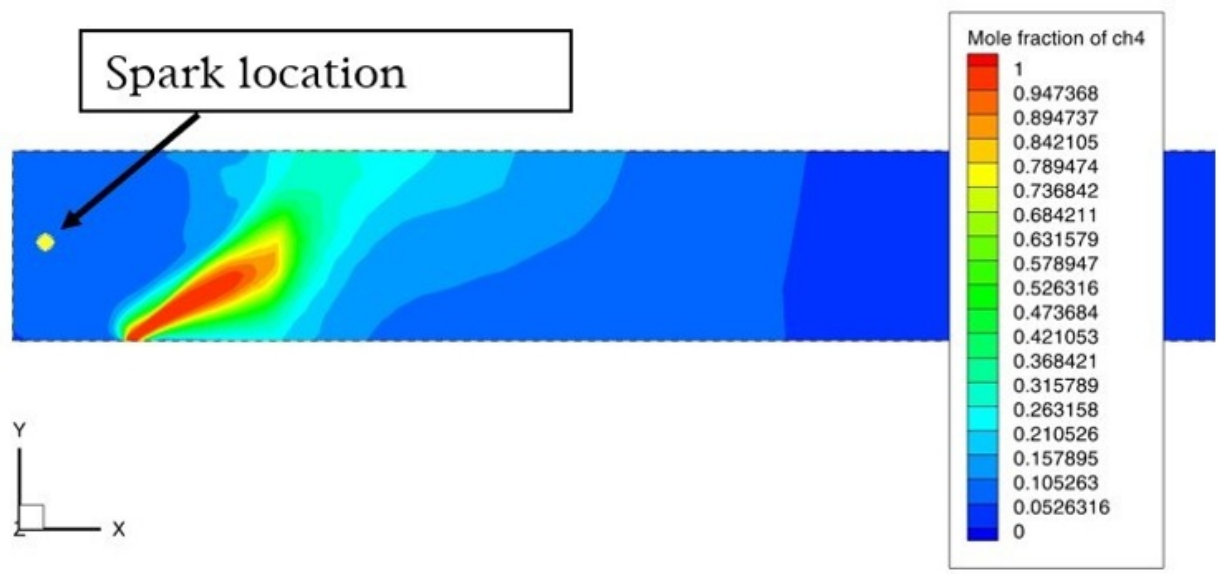

Fig. 3. Colour contours of the methane mol fraction and the location of the ignition source

Mainly, these differences are due to the irregular shape of the crack, but also to the differences between the temperatures of the combustible gas, of the environment in which it leaks and those of the limiting walls.

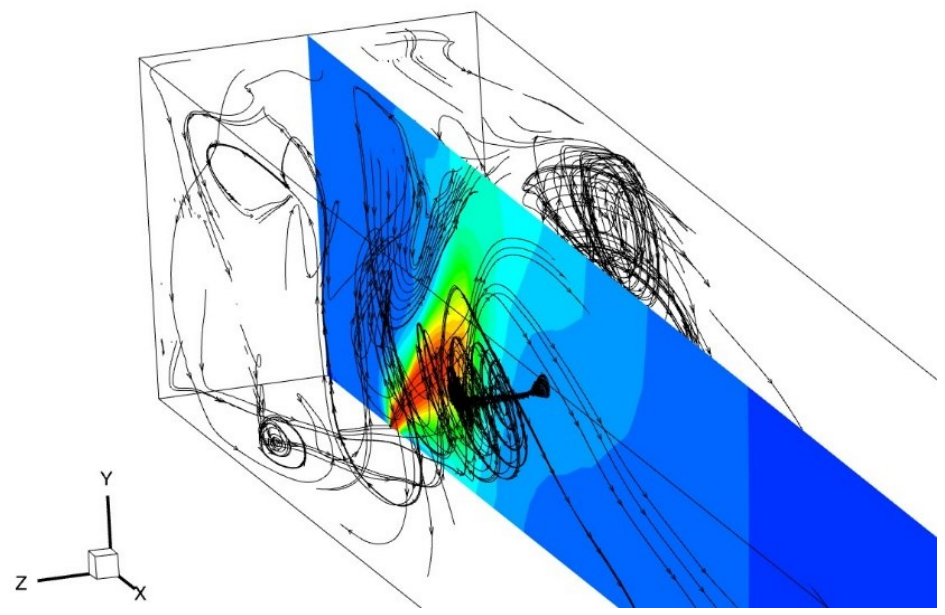

Fig. 4. Asymmetric arrangement of currents formed by the leakage of combustible gas

\subsubsection{Results}

As a first result of the simulation of the methane gas leak in the rectangular tube, the nonuniform dispersion of methane in the analysed volume was found. This inhomogeneity was preserved both in the longitudinal section and in the cross section of the tube.

Thus, the concentration of methane gas in the proximity of the spark location showed a higher growth rate than the global one, at the level of the entire volume. The methane oxidation reaction was initiated immediately after reaching the explosive range at the point of initiation, regardless of the concentration of methane in other areas of the rectangular tube.

This independence is highlighted by the graph in Figure 5 where, when the mole fraction at the point of initiation reaches 0.06 (so it enters the explosive range), the value of the same property (but read globally) is close to 0.03 . 
As a result of this moment, in which the ignition of the explosive mixture takes place, there is a decrease of the mole fraction as a whole, so that, later, the values of this parameter increase again due to the continuation of the methane leakage.

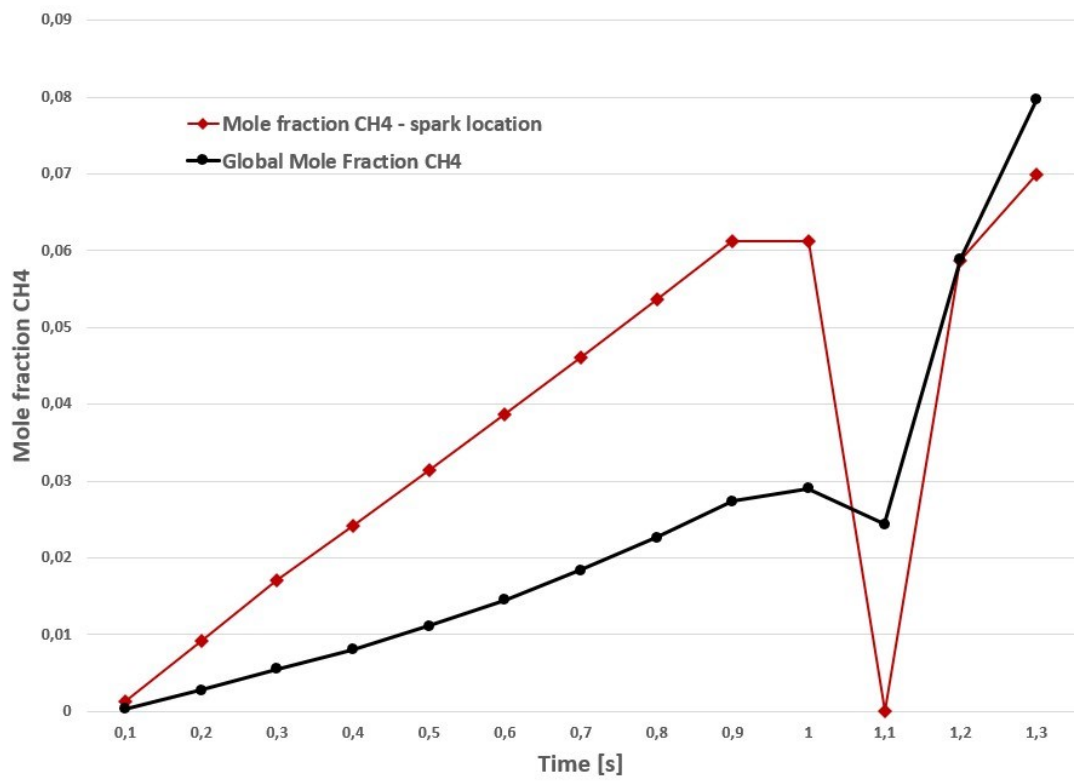

Fig. 5. Variations of molar fractions measured at the location of the spark and at the level of the entire volume of the tube

\subsection{Stage 2. Initiation of the explosive atmosphere}

In order to observe the ignition phenomenon of the explosive atmosphere formed in the previously described stage, the model made in the Fluent application was duplicated [8] within the ANSYS platform (figure 6).
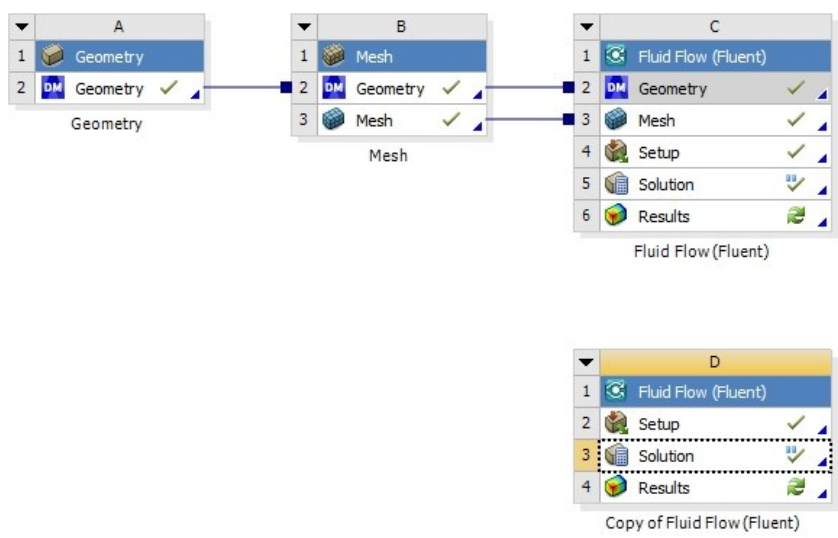

Fig. 6. Duplication of the model made in Fluent, for the realization of the second stage

Based on the settings from the previous stage, regarding the chemical reactions, the turbulence model, etc., in the new Fluent module the time step representing the moment of 
initiation of the explosive atmosphere was resumed - so the saved files were reloaded. Also, the computational simulation benefited from a refined time step, due to the transition to a regime with a higher velocities level than necessary to observe the diffusion of methane.

\subsubsection{Results}

As can be seen from Figures 7 a) to d), the initiation of the explosive mixture took place, followed by the propagation of the flame front on a certain portion of the rectangular tube.

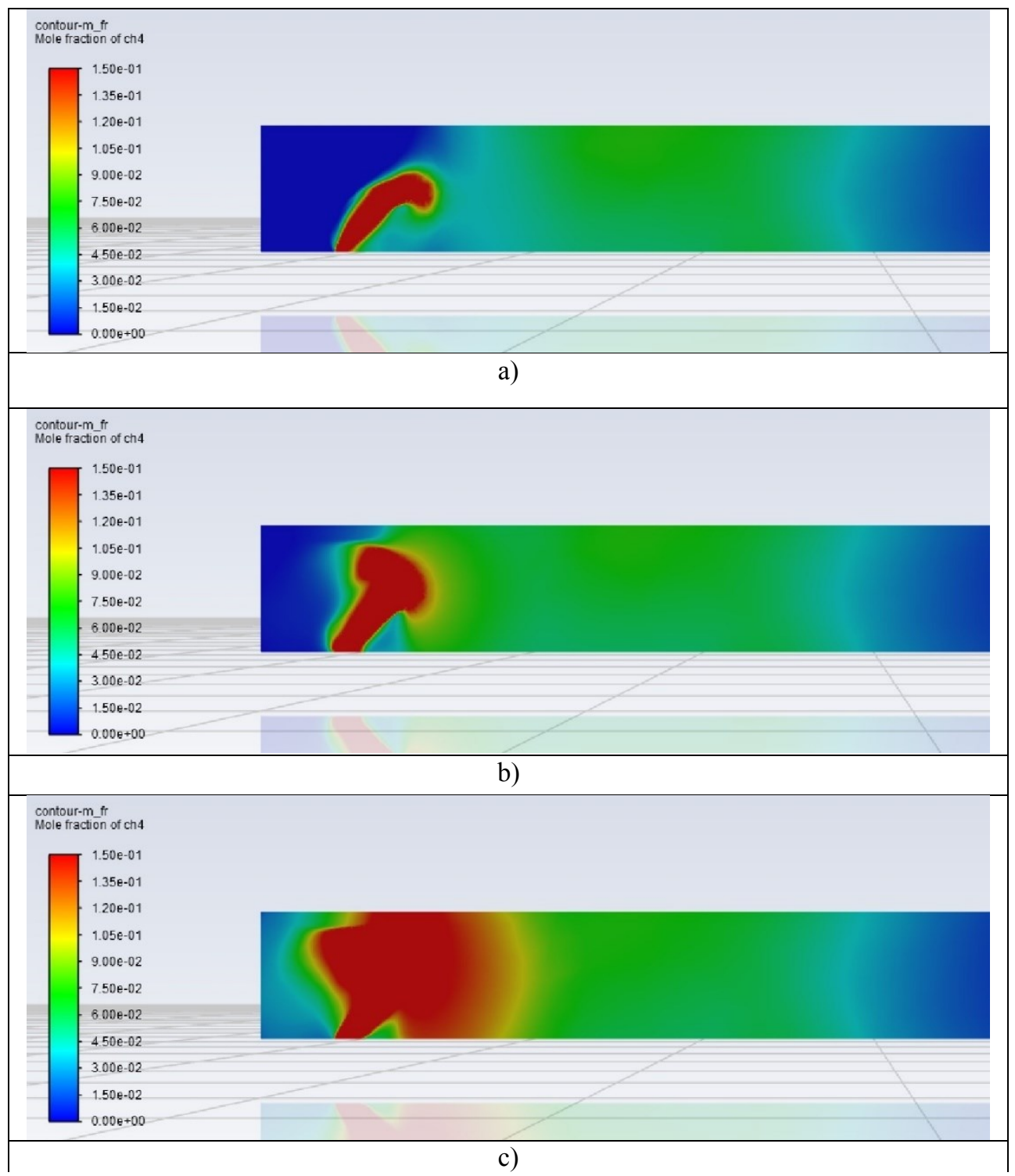




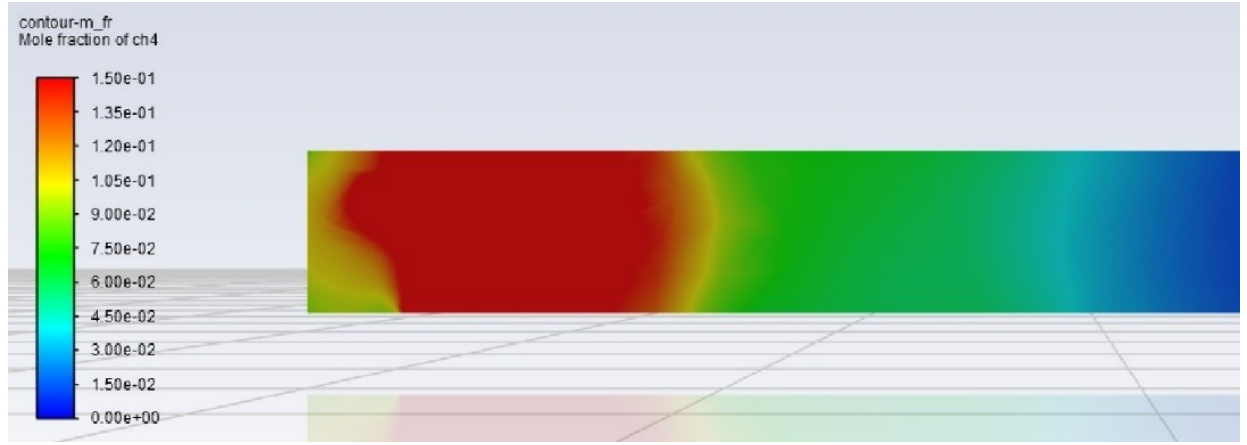

d)

Fig. 7. Colour contours of the $\mathrm{CH}_{4}$ molar fractions, recorded in the oxidation process of methane

In the first phase, part of the methane volume was burned leading to the expansion of the hot gases and pushing the other part of the methane volume to the exit of the tube. As the volume of oxygen decreased in the methane oxidation process at the closed end of the tube, the combustion was suppressed and the methane still entered through the crack, did not ignite (Figure 8, a to c).

This was followed by the cooling of the gases and subsequently, their retreat inside the tube, a phenomenon highlighted in the image in Figure $8 \mathrm{~d}$ ).

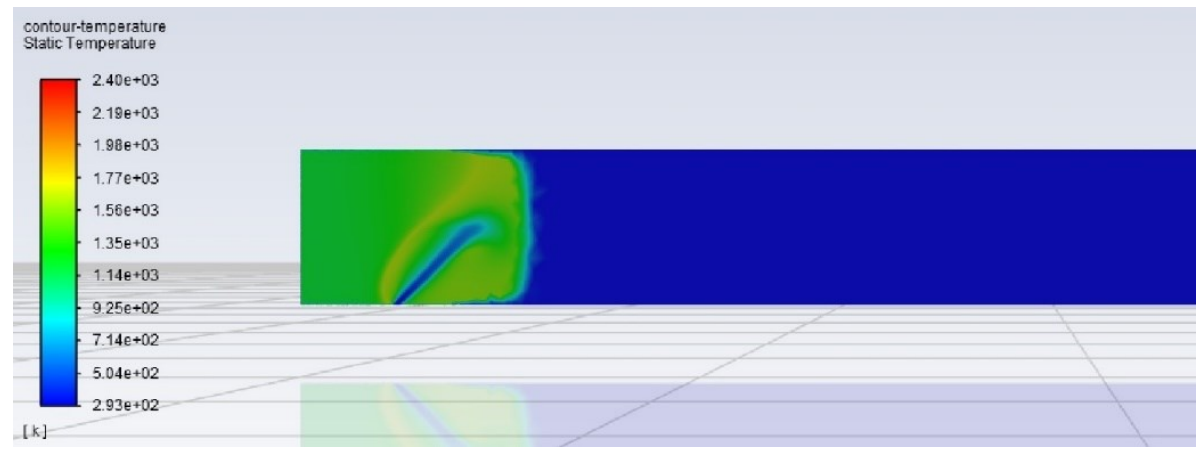

a)

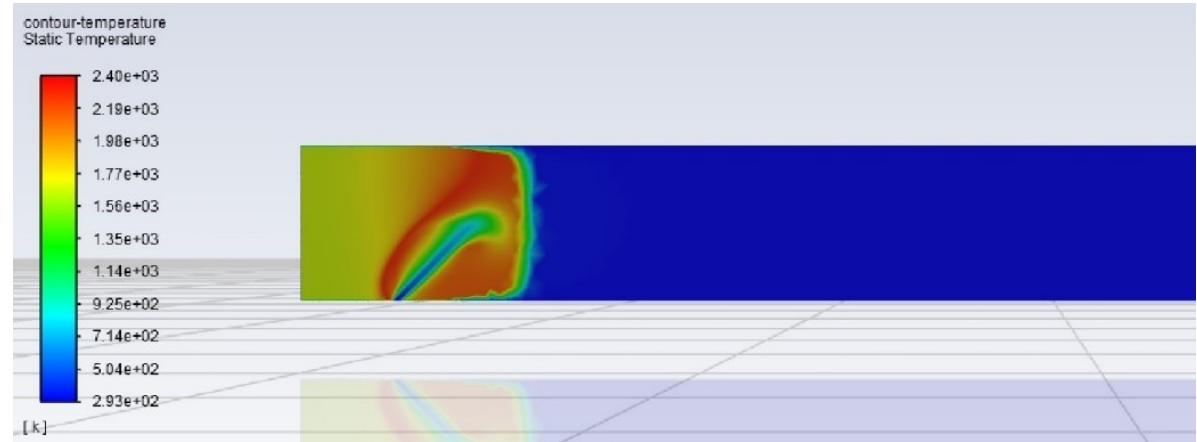

b) 


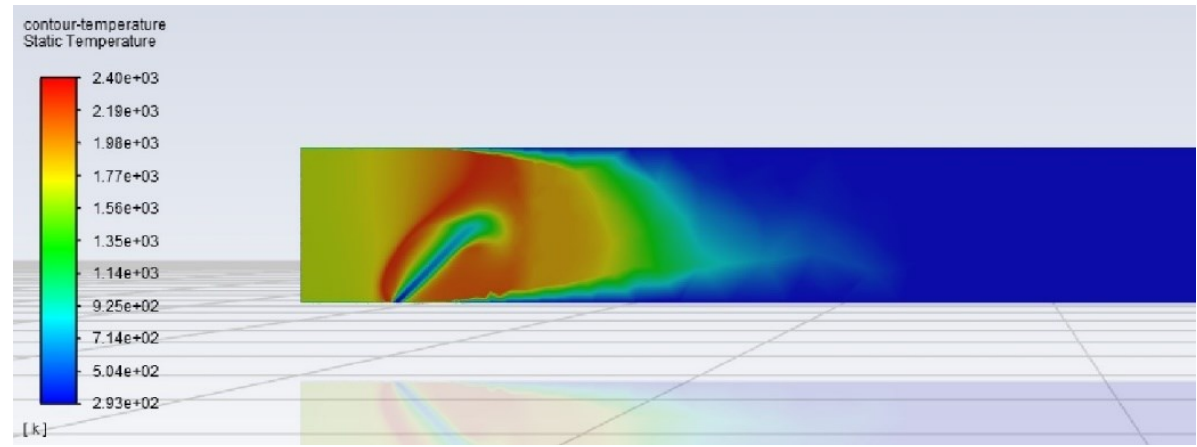

c)

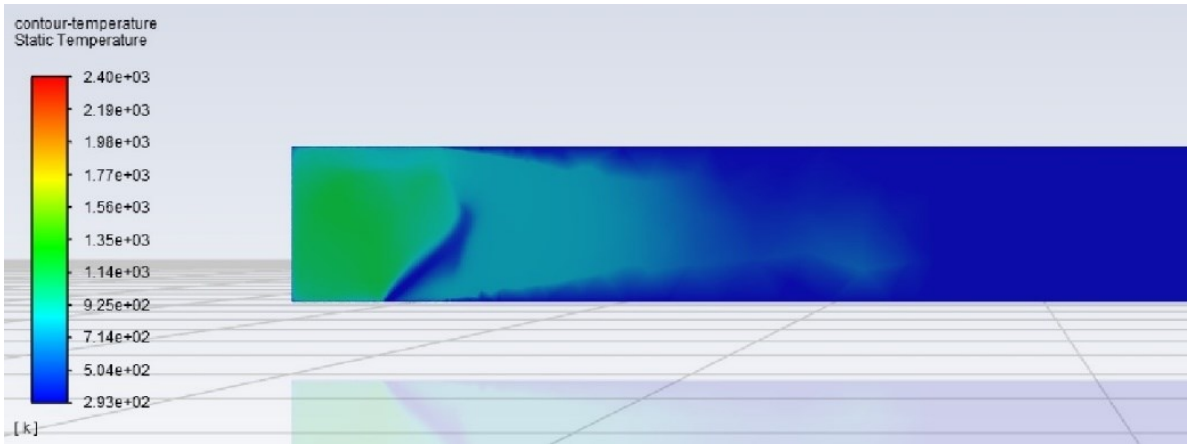

d)

Fig. 8. Colour contours of temperatures, recorded during the oxidation process of methane

\section{Conclusions}

From the above it appears that a calculation of the release of combustible gases is not enough to estimate the hazardous concentration in relation to the volume in which an explosion event can occur. It is necessary to make different scenarios in which to consider the possible sources of explosive gases, the possible locations of the initiation sources and the distance between them. However, the more solid objects the studied volume contains, the more complicated the situation becomes. In these cases, the use of CFD applications, the combination of their mathematical methods to obtain results with a high level of accuracy becomes increasingly stringent in the work of combating such events.

INCD INSEMEX Petrosani is accredited for the evaluation of the causes of the explosion type events and for the elaboration of the expertise reports. Thus, the method described above has direct and immediate applicability in the study of the event production mechanism. As an example, the case presented involves a small amount of reacted fuel gas. In reality, there can be an infinity of possibilities for the disposition of the cloud / clouds of flammable gas and as many geometric configurations of the affected space. In all these cases, the application of the method follows the same steps, the geometry of the space and the input data making the differences mirrored in the results. The validation of this kind of simulations is performed by comparing the effects obtained in the virtual environment with those observed during onsite research, on the explosion footprint.

This paper was developed within the Nucleu-Programme, carried out with the support of Romanian Ministry of Research and Innovation, project no. PN-19-21-01-05, project title: Fundamental research and computer simulations on the initiation of explosive gas mixtures 
by potential sources of ignition of a different nature (in Romanian: Cercetari fundamentale si simulari computerizate privind initierea amestecurilor gazoase explozive prin surse potentiale de aprindere de natura diferita).

\section{References}

1. A. B. Șimon-Marinică, D. Florea, Z. Vass, L. Munteanu, A. D. Băbut, SGEM 2020, Infrared scanning method for long distance identification and visualization of gases, (Albena, Bulgaria, 2020);

2. I. Glassman, Combustion, SE, (Academic Press, 1987);

3. C. Lupu, Methane from coal mines, (INSEMEX, 2007);

4. V.M. Pasculescu, S.M. Radu, E. Ghicioi, D. Pasculescu, T. Niculescu, SGEM 2014 Assessing the safety level of technical equipment operating in potentially explosive atmospheres by using computer modelling, (Albena, Bulgaria, 2014);

5. M. Prodan, E. Ghicioi, D. Oancea, EEMJ, Correlation of explosion parameters and explosion-type events for preventing environmental pollution (Iasi, Romania, 2014);

6. A. B. Șimon-Marinică, E. Ghicioi, N. Vlasin, M. C. Șuvar, D. Florea, SGEM 2019, Visualization and record methods for the initiation of air-methane explosive atmospheres (Albena, Bulgaria, 2019)

7. Tecplot 360 User's Manual, https://tecplot.azureedge.net/products/360/current/360_users_manual.pdf [Accessed 16.07.2021]

8. ANSYS Fluent User's Manual, ANSYS 2020 R1 Product, (2020) 